\title{
The Hidden Hazard of Household Air Pollution in Rural China ${ }^{1}$
}

Kristin AUNAN, CICERO, Norway, kristin.aunan@ @icero.oslo.no

Mette Halskov HANSEN, University of Oslo, Norway, m.h.hansen@ikos.uio.no

Zhaohui LIU, Zhejiang University, China, 651147892@qq.com

Shuxiao WANG, Tsinghua University, China, shxwang@mail.tsinghua.edu.cn

\section{Abstract}

Air pollution in Chinese cities has become a major topic of public debate and political concern. At the same time, few rural areas are subjected to measurements of ambient air quality, and policy documents and media rarely discuss the health and environmental risks caused by household air pollution (HAP) produced by the use of biomass for cooking and heating. Between 2014 and 2017 a cross-disciplinary team carried out a joint study of air quality and perceptions of air pollution in one of China's richest provinces, Zhejiang. We found that the ambient $\mathrm{PM}_{2.5}$ concentration in the rural villages was similar to that in the urban areas. Moreover, the 24-hour mean personal exposure to particulate pollution ( $\left.\mathrm{PM}_{2.5}\right)$ was similar for urban and rural participants in total. However, we found indications of enhanced exposure levels in certain sub-groups, such as biomass users, women, and family cooks. We found that while villagers were strongly concerned about risks of air pollution coming from nearby factories, they were largely unaware of the problem of HAP. In this article, we analyse to what extent HAP contributes to the air pollution exposure in the areas studied, and we discuss possible reasons why it has largely remained a hidden hazard. In the conclusion, we suggest that air pollution in rural areas should receive more attention from media, environmental organizations and policy makers; furthermore, that HAP in particular should be incorporated into air pollution policies to a greater extent, and its contribution to air pollution exposure in rural areas be made more publicly known.

\footnotetext{
${ }^{1}$ The authors contributed equally to the research and share lead authorship. We wish to thank the Research Council of Norway and the Sentre for Advanced Studies, Norway, for financial and other forms of support that enabled joint fieldwork across disciplines and the co-writing of this article.
} 
Keywords:

Household air pollution; China; rural air pollution; perceptions of pollution; risk of air pollution, gender and air pollution

\section{Introduction}

Outdoor, or ambient, air pollution (AAP) in China stems mainly from coal combustion in industry and power production, vehicles, burning of crop waste in agricultural fields, and household use of solid fuels for cooking and heating. The latter also results in indoor and neighborhood air pollution, known as household air pollution (HAP). One may assume that everyone residing within a given area is affected by the same level of AAP. However, people who rely on solid fuels for cooking or heating are, in addition, subject to HAP exposure because of the emissions from household stoves indoors. So far, research has not conclusively shown whether smoke from household stoves is more or less toxic than other types of particulate air pollution $\left(\mathrm{PM}_{2.5}\right)$, but it has been proven beyond doubt that household use of wood and coal in traditional stoves contributes considerably to air pollution in homes and neighborhoods (WHO, 2014). It has a critical impact on people's health, especially those who cook or spend time close to the source of pollution, often women and children. Improved stove campaigns have been launched in many parts of the world, and as early as the 1980s and 90s the Chinese government carried out programs that helped upgrade at least 130 million household stoves in rural areas. In practice, new so-called improved stoves had a chimney leading the smoke out of the house and a grate to improve combustion efficiency (Sinton et al. 2004). About 25 years later after these campaigns, China census data show that nearly half the Chinese population continues to rely fully or partly on solid fuel for cooking and heating (NBS, 2012). It has been estimated that around 280 million people in China, or one fifth of the population, will still be doing so by 2030 (The World Bank 2013).

In this article, we use results from our interdisciplinary fieldwork to discuss the role of HAP in the context of the health risks of air pollution in rural China, and to explore how local people themselves perceive of the risks of ambient versus household air pollution. While outdoor air pollution especially in urban areas has become an intense topic of debate in China, there is little mention of HAP in media and even in policy documents regarding air pollution (Gao 2017; Hansen and Liu 2018; Li and Svarverud 2018). HAP, we argue in this article, may in fact be considered an example of a hidden hazard in the sense discussed by Kasperson and Kasperson (2005) who ask why some hazards and risks are amplified in society while others 
receive limited attention in spite of there being established knowledge of them. There are many reasons why some recognized hazards remain out of the limelight and evade scrutiny and mitigating action by society. Most importantly, the ways in which hazards and risks are identified, perceived and communicated are embedded in value systems, scientific practices, and social and political relations. In some cases, political authorities may attempt to keep recognized hazards hidden from the public to avoid instability. More complex cases concern dynamics of integrated corporate interests and politics, as in the case of US companies' promotion of tobacco usage worldwide despite the well-established fact of its serious health impacts. HAP is an example of a hazard that has been recognized both by scientists and policy makers in China for quite some time. Yet in spite of the large-scale campaigns in the 1980s and 1990s to promote energy shifts in rural areas, it is only since 2016 that systematic measurements of air quality are slowly being introduced in rural areas and these measurements so far target only ambient air pollution. Furthermore, unlike urban air pollution data, the results from rural areas are not yet made open to the public. HAP mainly affects the rural poor who use biomass or coal for cooking and heating. It has received little media coverage and there are, to the best of our knowledge, no environmental NGOs in China that address HAP. In our studies of air pollution and perceptions of it in China we also found a very low level of knowledge and acknowledgement of the problem of HAP in the population and local governments.

In the following, we build on a combination of qualitative anthropological data and scientific air pollution data collected jointly by scholars from different academic disciplines in one of the more affluent rural areas of China, Quzhou in Zhejiang Province. We analyze how HAP contributes to exposure to health-damaging $\mathrm{PM}_{2.5}$ pollution for rural residents, and we explore how villagers perceive the risks of air pollution and what may lead them to change practices of fuel use. Finally, we conclude with some preliminary policy suggestions related to the importance of integrating HAP into air pollution policies, and making HAP a publicly acknowledged rather than a hidden hazard.

\section{The Health Effects of HAP}

Access to clean household energy is still a luxury for most of the world's poor. Currently, almost 3 billion people rely on solid fuels, such as wood, crop residues, animal dung, charcoal, and coal for cooking or heating (World Health Organization 2014, 152). Typically, 
these fuels are burnt in simple stoves or fireplaces, resulting in incomplete combustion and large emissions of particulate matter and other toxic air pollutants (Naeher et al. 2010). Although there is abundant evidence that HAP is a major cause of global ill health, there are few studies of exposure to HAP and its health effects as compared to the multitude of corresponding studies of urban AAP. ${ }^{2}$ Particularly in the US and Europe, large-scale and long-term epidemiological studies have produced firm quantitative estimates of the health damage from urban AAP (e.g. Brunekreef 2007; Pope et al. 2002). Such studies have contributed to the establishment of ambitious air pollution policies, and concentration levels in ambient air of, for example, sulfur dioxide $\left(\mathrm{SO}_{2}\right), \mathrm{PM}_{2.5}$ and surface ozone $\left(\mathrm{O}_{3}\right)$ have started to decline in many regions (Guerreiro et al. 2016). ${ }^{3}$

In comparison, there is a remarkable lack of studies of the health impacts of HAP and, especially, the role of HAP for the total exposure to air pollution in the population. Usually, AAP and HAP are treated as separate health risk factors. For instance, the Global Burden of Disease Study estimated that 2.9 million people in the world died prematurely due to HAP in 2015, as compared to an estimated 4.2 million deaths due to ambient $\mathrm{PM}_{2.5}$ pollution (GBD, 2016). For China, the corresponding estimates were 0.59 and 1.11 million, respectively. ${ }^{4}$ Importantly, these estimates assume that AAP contributes little to exposure among solid fuel users, which may not always be correct. In many regions, including rural China, HAP will be present in addition to high levels of AAP, and emissions from household stoves may in themselves be an important source of AAP (Butt et al., 2016; Conibear, Butt, Knote, Arnold, \& Spracklen, 2018; Liu et al., 2016). Treating AAP and HAP as two sides of the same coin, i.e. as two potential sources of personal $\mathrm{PM}_{2.5}$ exposure, may result in substantially altered health burden estimates (Aunan et al., 2018; Zhao et al., 2018)

Since the mid-1990s, studies from China have addressed the health effects of air pollution in urban areas, and thanks to the expanding monitoring system in urban areas since the 2010s, this research is rapidly increasing (Aunan and Pan 2004; Jacobs et al. 2017; Wang et al. 2017; Yin et al. 2017; Nielsen and Ho 2013). Yet, studies of health effects of air pollution in China rarely take into account people's exposure to HAP, and rural areas are often omitted entirely from studies of health and economic risks of air pollution. For instance, a recent study of the economic consequence of AAP in China demonstrated considerable

\footnotetext{
${ }^{2}$ See summary of HAP research in World Health Organization (2014).

${ }^{3}$ US EPA, 2016. National Air Quality: Status and Trends of Key Air Pollutants https://www.epa.gov/air-trends (accessed 10 May, 2018).

${ }^{4}$ IHME, 2016. GBD Compare, October 2016. https://vizhub.healthdata.org/gbd-compare/ (accessed 15 June, 2017).
} 
socio-economic costs for society, but excluded rural areas from the study because of a lack of data (Matus et al. 2012). This scarcity of studies addressing AAP in rural areas may also be related to the erroneous perception that air pollution levels in non-urban or industrialized areas are low, and this again leads to limited political attention and funding for monitoring programs (see Aunan et al. 2018a and references therein). When it comes to HAP measurements in China and elsewhere, these are scarce and have been done only in short-term on-and-off research efforts involving relatively few households. Aunan et al. (2018b) found merely nine studies that had measured $\mathrm{PM}_{2.5}$ exposure among solid cooking fuel users in rural settings across China for the period 2008-2017. The crude mean of all data-points for personal $\mathrm{PM}_{2.5}$ exposure (for men and women, and for summer and winter) was 220 (SD 156), which is more than six times the Air Quality Standard set for Chinese cities. The technical challenges with measuring air pollution at the household and individual level, the variation in fuel use and stove types, and, sometimes, problems of gaining research access, may partly explain the scarcity of HAP studies. As we discuss below, we doubt it is the full explanation.

Lately it has become clear to scientists that HAP emissions from rural cooking and heating stoves may be an important source of AAP also in many urban areas due to long range transport of air masses. In the Beijing area, for instance, as much as 40 per cent of the AAP concentration in winter time may be due to stove emissions (Liu et al. 2016). Such findings in urban areas might typically lead to increased attention in media, and they have already led to efforts to include HAP emissions in abatement plans (e.g. Ministry of Environmental Protection of China 2017). At the same time, the issue of HAP exposure and associated health risks among the solid fuel users themselves, that is, the risk to poorer rural populations, does not appear to be the main political motivation for this change; and there are also relatively few studies of how rural health is affected by HAP, studies that would support a change of policies. Furthermore, there is an even larger knowledge gap regarding how rural populations perceive the risk of HAP as compared to other pollution risks. In a study among rural poor households in the less developed provinces of Guizhou, Shaanxi, Gansu and Inner Mongolia about knowledge of health hazards related to tobacco smoke and smoke from cooking and heating fuels, scholars found that even among illiterate residents more than half were well aware that smoke from cooking and heating fuels constituted a health risk. However, the study also showed that the knowledge of methods for reducing the smoke from these fuels was limited, with the exception in Inner Mongolia where a government program to improve indoor air quality had recently had been implemented, raising the population's awareness of the problem and providing possibilities for limiting the health risks from HAP 
(Jin et al., 2005). It is against this backdrop that we, in 2014, started up an interdisciplinary study of HAP in a rural area of Zhejiang Province.

\section{Field Sites and Research Methodologies}

Our research was carried out between 2014 and 2017 within the administrative city (shi) of Quzhou, a national hub for chemical industry. ${ }^{5}$ Quzhou has 2.1 million inhabitants and comprises a number of villages within a distance of 10-20 kilometres from the urban centre. Whereas the air quality in Zhejiang Province is generally better than in many other regions of China, ${ }^{6}$ Quzhou ranked number 185 out of 359 cities, with number one being the cleanest one, in the first half of $2016 .{ }^{7}$ In 2014 , there were 11 measuring stations established in the urban areas of Quzhou, and the city's annual mean level of $\mathrm{PM}_{2.5}$ was $57 \mu \mathrm{g} / \mathrm{m}^{3}$. On the worst days, the level of air pollution was several hundreds of $\mu \mathrm{g} / \mathrm{m}^{3}$, and while this was far below the level of the most critical days in cities such as Tangshan, Shijiazhuang, or even Beijing, it was well above the National Air Quality Standard of $35 \mu \mathrm{g} / \mathrm{m}^{3}$. In 2010, more than 80 per cent of Zhejiang Province's households used mainly gas or electricity as cooking fuel, but in Quzhou 37 per cent of households used solid fuel on a regular basis, according to local official statistics. ${ }^{8}$ This was the highest percentage of household use of solid fuel among the prefectural cities in Zhejiang, one of the richest provinces in China. Quzhou also had the highest proportion of rural population, ${ }^{9}$ and the lowest level of average education (Zhejiang Statistics Bureau 2014, pp. 190 and 200).

For comparative reasons, our study was conducted in two urban neighbourhoods in Quzhou, and in a cluster of villages outside of the city centre. These villages were located less than three kilometres from a recently established industrial park, and they were even closer to village factories producing, among other things, bricks. ${ }^{10}$ As in most other rural areas of China, there had never been any official systematic measurements of air quality over time in

\footnotetext{
${ }^{5}$ Studies of pollution in China that involve both natural scientists and social science scholars are rare, and gaining access to fieldsites is increasingly difficult, especially when projects involve researchers from institutions outside of China. Our choice of fieldsites was largely due to academic and local contacts which made the study possible.

${ }^{6}$ http://www.chinadaily.com.cn/china/2017-01/22/content_28023186.htm (accessed 18 January, 2018).

7 http://www.greenpeace.org.cn/wp-content/uploads/2016/07/2016 年上半年 PM2.5 平均浓度省份排名.pdf (accessed 18 January, 2018).

${ }^{8}$ Office for the Population Census of Zhejiang (2012) 5:3169-3170.

${ }^{9}$ Office for the Population Census of Zhejiang (2012), 1:52-52 and 292-297.

${ }^{10}$ See Hansen and Liu (2018) for more details on field sites, village perceptions of air pollution, and the staging of local protests against some of the local industry.
} 
or near these villages. ${ }^{11}$ During our six periods of fieldwork, each lasting between one and three weeks, between 2014 and 2017, the authors (together with hired student assistants) used research methodologies from the natural and social sciences to collect data on the levels of air pollution in indoor and outdoor environments, people's personal exposure to air pollution, local perceptions and ways of dealing with air pollution, and local policies of air pollution. ${ }^{12}$

We conducted a 300-household survey of which 200 households were located in two different urban communities and 100 households were located in two villages 12-15 kilometres from the urban centre of Quzhou. The urban participants lived in apartment buildings in the city center, and all had access to clean household fuels (gas/LPG and electricity). While the location of the villages can by no means be characterized as "remote", they were nevertheless not affected by heavy traffic, and one of them was located on the edge of a forested hill. They were, however, only a few kilometers away from a recently constructed industrial park. The villagers we studied lived in older traditional one- or twostory houses or, sometimes, in more recently constructed two- to four-story houses. Many families owned both a traditional and a more modern house, and although most used LPG for daily cooking, all of the 100 surveyed households had their own traditional biomass stove (tuzao) either within their house of residence, or built in a construction adjacent to it (the last being common for people living in newer houses). In general, households were characterized by a substantial mix in the cooking fuels they used, so-called fuel stacking. Our survey contained questions regarding size of households, levels of education of householders, occupation of householders, knowledge of air pollution, smokers in the family, use of fuel for cooking and heating, etc. It formed the basis of an additional nearly 100 in-depth qualitative interviews (some of them with individuals, others in focus groups) with a large number of open questions about views on air pollution and other forms of pollution, agricultural practices and historical changes related to the use of fuel, experiences with pollution related protests, perceptions of health and disease, economic changes in the area, etc. Interviews were carried out with residents of both genders who were mostly between 20 and 75 years of age, with immigrant brick factory workers from the much poorer province of Guizhou, and with local officials and village cadres. All interviews were done in the villages (in Mandarin) and

\footnotetext{
${ }^{11}$ In 2014, however, the government initiated a pilot project to measure ambient air quality in some selected rural area. In 2015 measurements began to be taken, including in the prefecture of Kaihua in Quzhou. The first figures are from 2016 and have not yet been made public.

${ }^{12}$ The research was part of the larger Airborne Project, and we gratefully acknowledge the funding received from the Research Council of Norway and the Norwegian Centre for Advanced Studies. More publications from this larger project may be found on the project website https://www.hf.uio.no/ikos/english/research/projects/airborne-pollution-china/.
} 
most were recorded and anonymized. In addition, throughout our fieldwork periods we engaged in a number of shorter and longer informal conversations with people we encountered, and we did some anthropological participant observation during the harvesting and processing of oranges (for more details, see Hansen and Liu 2018).

We collected data on $\mathrm{PM}_{2.5}$ concentrations as follows: Measurements of kitchen concentrations of $\mathrm{PM}_{2.5}$ were carried out during three periods of fieldwork, one in late summer (September 2015) and two in the winter season (January 2016 and January 2017), each period lasting two weeks. During each of the first two fieldwork periods we installed measuring devices in 25 rural and 25 urban households that were part of the survey and interviews. Among these 50 households, we recruited 12 urban and 12 rural residents, identified by their own household as the family's main cook, to wear a portable $\mathrm{PM}_{2.5}$ monitor for a period of 24 hours. In the third round of fieldwork, we continued indoor and personal measurements in the rural areas, resulting in a total of 124 kitchen measurements and 80 personal measurements (several sample kitchens and persons were recruited in more than one field period).

The kitchens and personal PM$_{2.5}$ levels were monitored using a UCB Particle and Temperature Sensor (PATS+) which is a $\mathrm{PM}_{2.5}$ monitoring instrument developed by Berkeley Air Monitoring Group. ${ }^{22}$ The PATS+ is a small, portable data logging device that uses an optical scattering sensor to measure real-time $\mathrm{PM}_{2.5}$ concentration. In our study, this device was fixed to the kitchen wall and on the upper arm of participants for 24 hours for uninterrupted sampling. The data from PATS+ were calibrated by filter sampling using BAM 1020 Beta Attenuation Mass Monitor (Met One Instruments, Inc., USA). In addition to the kitchen and personal sampling, four outdoor locations in each of the two villages were selected for PATS+ sampling and filter sampling of ambient $\mathrm{PM}_{2.5}$ during the fieldwork in January 2017. ${ }^{13}$ We also collected official online outdoor $\mathrm{PM}_{2.5}$ data from the urban monitoring stations in Quzhou during the three study periods.

\section{Local Perceptions and Policies of Air Pollution}

Villagers in Quzhou warmly welcomed our research team when we first arrived in 2014. They approached us with stories of horrendous air pollution from factories producing plastics, bricks, tiles, Christmas items and other products. They had to keep windows and doors closed when the wind was blowing from the industrial park in their direction, and many were

\footnotetext{
${ }^{13}$ We used a temporal logging resolution of $10 \mathrm{~s}$. The lower detection limit is $10 \mu \mathrm{g} / \mathrm{m}^{3}$. For more details regarding technical aspects of measurements and results, see $\mathrm{Hu}$ et al. (work in progress).
} 
convinced that incidents of leukaemia, breast, lung, skin and uterine cancer were connected to polluted water and air caused by industry since the 1980s, continuing and worsening into the present. They had a history of protesting against air pollution and were, at the same time, well aware that the government was putting new efforts into solving the issue of urban air pollution (Hansen and Liu 2018). When we told them that our team was particularly interested in measuring their exposure to household produced air pollution they reacted with incredulity. Of all the environmental problems they were facing, air pollution from industry being a major one, why would we be interested in their cooking methods! This reaction, however, should not be mistaken for ignorance of the potential health impacts of cooking with solid fuels. In our attempts to outline villagers' history of fuel transition through conversations and group interviews, it had become clear that while availability and price unsurprisingly played the major role in villagers' decisions about which fuels to use for cooking (and in the short cold periods also for heating), there were also considerations of the indoor environment and convenience for the cook, who was mostly, but not always, a senior female in the household.

Cultural habits, economic considerations and policy awareness all played a role in villagers' choice of fuel. Wood had always been the preferred form of fuel, and it was still regarded by villagers as an effective and relatively clean form of fuel. However, it had been in short supply and therefore expensive in recent history, and during the 1960s and 70s (for some families even well into the 1980s) people often had to rely on dry grass, peat, rice straw, maize stalks and dried cow dung as household fuel. In the late 1960s, villagers discovered easily accessible coal in their area, but the advantage of free fuel was mitigated by the fact that ironware in households, for instance, iron on windows and doors, cooking utensils and agricultural tools, corroded because of the sulphur in coal. Villagers knew very well that what they in daily vocabulary referred to as "non-smoking coal" (and what scientists refer to as "anthracite") was the best form of coal, but it was too expensive for them. In the early 1980s, it was even rationed and only people working in state units (danwei) were given the necessary coal coupons (meipiao) to buy it. The village was connected to the electricity grid in 1980, but electricity was also considered very expensive so villagers turned to cheaper kinds of coal from the north that eventually became more abundant up through the later 1980s and 90s. With growing incomes in the 1990s, villagers gradually started to use LPG as their major form of fuel. Conversations about issues of fuel use and perceived connections between quality of air and health were complex, and beyond the scope of this article. However, our conversations with villagers about their recollections of the local history of energy use and 
transitions clearly showed that cultural practices and preferences of fuel use were inseparable from economic considerations and policy implementations. The villagers had, for instance, been prompted to use more wood as fuel, instead of poor-quality coal, grass, straw, etc., when new economic policies beginning in the 1980s allowed for private households to contract their own forest areas (in addition to fields) and secure access to wood. Later, in the early 1990s, villagers had, in their own account, been very keen to join a local government project to install methane gas in households as a new and clean form of energy. However, to their dismay, they had not been given this chance because this particular energy policy was only aimed at villages with a high number of hog farms.

When we arrived in 2014, practically all households continued to use a mix of fuels that illustrated a longer local history of energy use and transitions. With a few exceptions all villagers had a gas stove, and most households used it for cooking when only one or two people were at home. In addition, they had an electric rice cooker and a traditional biomass stove. Biomass, in the form of free and easily accessible prunings from the villagers' orange trees, were the preferred form of fuel for cooking meals for large groups of people, when children and grandchildren came home for the weekend, or when traditional dishes were made for major celebrations such as New Year or weddings. In the poorest households the biomass stove was used on a daily basis. It was also the biomass stove that received small offerings for the Kitchen God and to which new paper prints with images of the Kitchen God were attached for New Year in order to protect against evil spirits. Further epitomizing the village's brief history of fuel mix and transition, many families had preserved their old coal stove, now using it simply as an extended kitchen table. All other devices - traditional biomass stove, electric rice cooker, LPG cooker, for a few families even a microwave oven-remained in use, but at different times and for different purposes.

Demonstrating their knowledge of the negative impact of certain cooking fuels, villagers repeatedly emphasized that gas as compared to coal and wood was clean and convenient, and, importantly, free of smoke. They had therefore, during the 1980s and 90s on their own initiative, built chimneys to lead the smoke out of their houses, first out the side of the house, which often created conflicts with neighbours, then later, through the roof. When asked if they would return to using coal as a fuel if it was provided to them for free and delivered to their houses, only one person in a group of about 20 people discussing the issue responded "yes, if it was convenient." His affirmation was immediately met with a roar from other villagers who insisted that coal was "dirty" and "bad" for the indoor environment, even for the global environment, some argued. At the same time, villagers agreed that they now 
used what they considered were basically clean forms of fuel, namely LPG and wood, in the traditional biomass stove, and not rice straw, cow dung, or coal, which they considered hazardous. Their indoor air was now good, they agreed, and the only air pollution problem they had was due to the neighboring industry. ${ }^{14}$ Unfortunately, our measurements of $\mathrm{PM}_{2.5}$ in people's houses suggested otherwise, as we discuss in the following.

\section{Air Pollution and Personal Exposure in the Villages}

Like other studies of HAP in China, our samples are limited in time and scope, but they support previous findings showing that HAP constitutes a considerable health risk in rural areas. Our measurements of outdoor air pollution were done in January 2017, shortly before Chinese New Year when rural migrant workers return home for up to one month, and many local factories were therefore not in operation in the period we were taking measurements. This explains why villagers during this period did not experience any incidents of the heavy "rain-like grey" air pollution they complained regularly came directly from the industrial park, especially at night, forcing them to close windows and leaving a grey layer of dust on plants and trees. Furthermore, the January 2017 fieldwork was about three months after the international forum known as G20 held its meeting in the provincial capital of Hangzhou, causing the Chinese government to require an unusually large number of factories to shut down for a period of time, in order to keep the sky blue in the city while major political leaders were gathering there. This also affected factories in the industrial parks of Quzhou, and some had not yet returned to full levels of production by the time we arrived to do our fieldwork. Consequently, the results of our measurements reflected the situation at a period of time when the outdoor air was comparably good and definitely not at its worse. In addition, obviously, our results are from a comparatively affluent rural area with relatively low use of biomass as compared to much poorer rural areas in inland and western parts of China.

Overall, we found that the $\mathrm{PM}_{2.5}$ concentrations in ambient air in the villages were similar to the official monitoring data from the urban areas of Quzhou. Over the nine-day period in January 2017 when we measured ambient $\mathrm{PM}_{2.5}$, the mean concentration in the two villages was 53 (S.D. 48) $\mu \mathrm{g} / \mathrm{m}^{3}$, with a range of $25-118 \mu \mathrm{g} / \mathrm{m}^{3}$. The corresponding level from

\footnotetext{
${ }^{14}$ There were also significant gender and age differences determining methods and preferences of cooking which we do not have space enough to account for here.
} 
the official urban online monitoring station closest to the villages was 45 (S.D. 23 ) $\mu \mathrm{g} / \mathrm{m}^{3}$, with a range of $18-102 \mu \mathrm{g} / \mathrm{m}^{3}$.

Figure 1. Daily mean PM2.5 concentrations in ambient air measured in the two rural villages and in urban Quzhou during fieldwork in January $2017\left(\mu \mathrm{g} / \mathrm{m}^{3}\right)$.

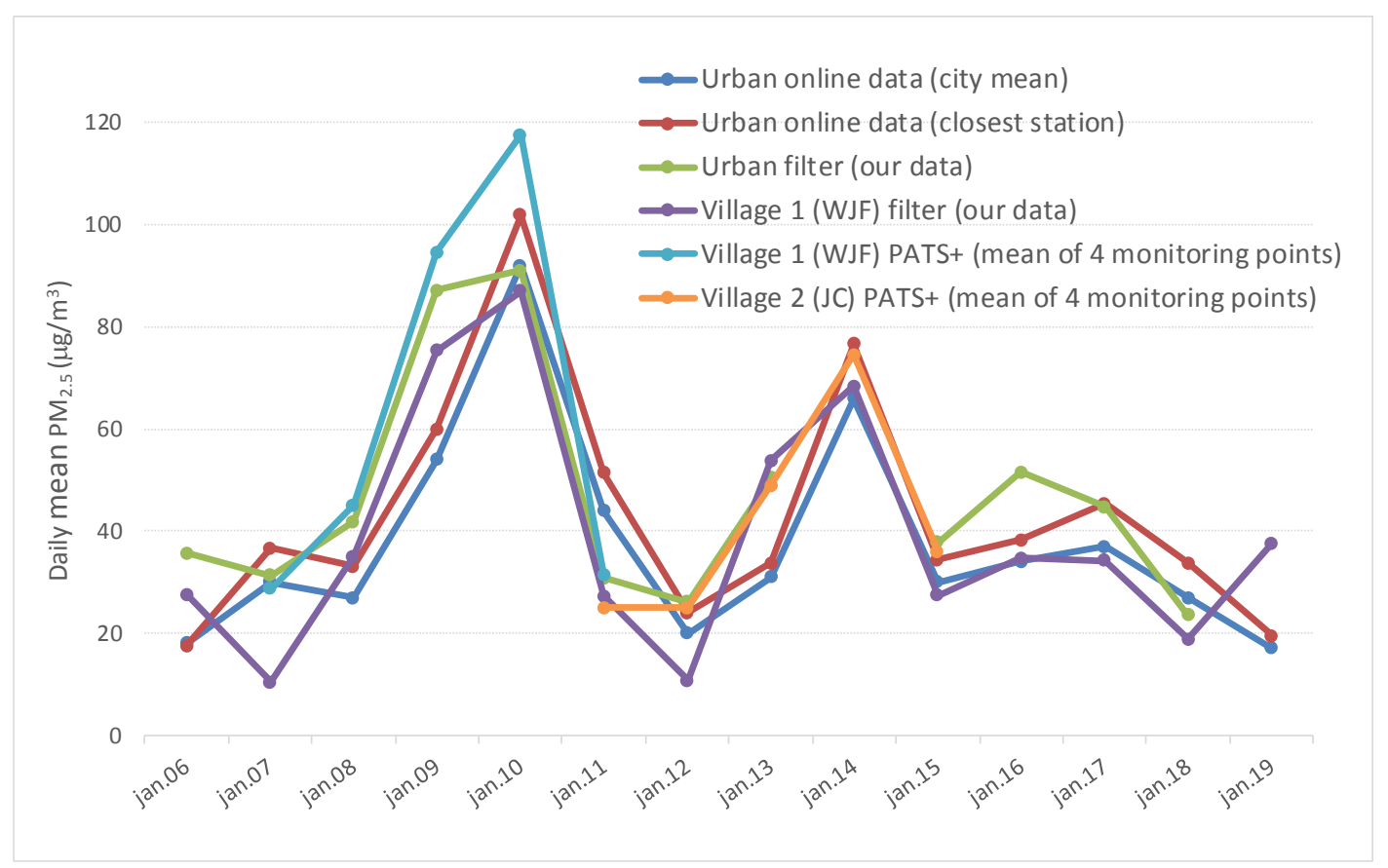

Also, for all three study periods the 24-hour mean personal exposure was similar across the urban and rural settings, with a mean value across all participants and field periods of 59 (S.D. 37) $\mu \mathrm{g} / \mathrm{m}^{3}$ in the city and 59 (S.D. 33) $\mu \mathrm{g} / \mathrm{m}^{3}$ in the villages. However, the rural participants who used biomass as fuel for cooking on average had higher personal exposures than their rural neighbours who used clean fuels like LPG and electricity (64 (S.D. 30) $\mu \mathrm{g} / \mathrm{m}^{3}$ and 55 (S.D. 36) $\mu \mathrm{g} / \mathrm{m}^{3}$, respectively, for biomass and clean fuel users). Whereas the difference between biomass users and clean fuel users was not statistically significant, a much higher indoor concentration of particulate matter in the kitchens of biomass users likely contributed to an enhanced mean personal exposure. We found that kitchen concentrations of $\mathrm{PM}_{2.5}$ during cooking was on average 215 (S.D. 97) $\mu \mathrm{g} / \mathrm{m}^{3}$ in the homes of biomass users, whereas the corresponding value in the rural kitchens using LPG or electricity was, 
respectively, 58 (S.D. 23) $\mu \mathrm{g} / \mathrm{m}^{3}$ and 45 (S.D. 3) $\mu \mathrm{g} / \mathrm{m}^{3}$. We found overall higher personal exposure levels for women than for men, 62 (S.D. 37) $\mu \mathrm{g} / \mathrm{m}^{3}$ in women versus 52 (S.D. 25) $\mu \mathrm{g} / \mathrm{m}^{3}$ in men. Again, the difference was not statistically significant, which may be related to the low sample size. For the rural sample as a whole, the daily mean $\mathrm{PM}_{2.5}$ exposure was 61 (S.D. 33) $\mu \mathrm{g} / \mathrm{m}^{3}$ for cooks and 36 (S.D. 28) $\mu \mathrm{g} / \mathrm{m}^{3}$ for non-cooks. Most rural families had at least one smoker (always a male) and we found that smoking affected the indoor $\mathrm{PM}_{2.5}$ levels. Still, in households where biomass was used for cooking, the biomass burning clearly had the largest impact on the air quality.

Using time-activity data in combination with personal exposure data for separate microenvironments for the rural population, we found that in spite of the fact that less than three hours were spent in the kitchen (on average for all participants), the exposure in kitchens constituted 26 per cent of the total daily exposure. The total time spent outdoors was on average 2.3 hours, which contributed 8 per cent to the daily exposure burden. The remaining exposure was related to other indoor environments, including staying in the living room and bedroom. When we compared biomass users and clean fuel users (rural only), we found that biomass users spent on average 3.3 hours in the kitchen and that this contributed to 40 per cent of their total daily exposure. Clean fuel users, on the other hand, spent on average 2.5 hours in the kitchen, and the time spent in the kitchen contributed only 13 per cent of the total daily exposure for this group (Figure 2). Women spent more time per day in the kitchen than men, on average 3.1 (S.D. 1.0) hours versus 2.3 (S.D. 1.4) hours, and older women, especially those between 65 and 80 years, spent the highest number of hours in kitchens of all participants.

Figure 2. Contribution of exposure in microenvironments to total personal PM 2.5 exposure in the rural villages. a) for biomass users; b) for clean fuel users (LPG or electricity). 
a)

\section{Rural biomass users}

(24 h mean personal exposure 64 (SD 30) $\mu \mathrm{g} / \mathrm{m}^{3}$ )

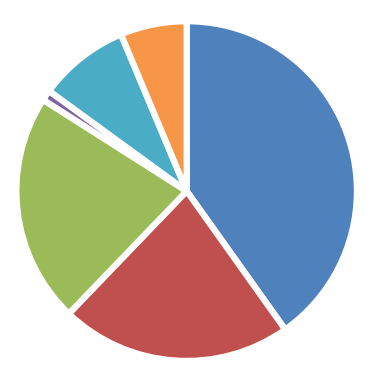

- Kitchen

- Living room

- Bedroom

- Traffic

- Indoor activities

- Outdoor

b)

\section{Rural clean fuel users}

(24 h mean personal exposure 55 (SD 36) $\mu \mathrm{g} / \mathrm{m}^{3}$ )

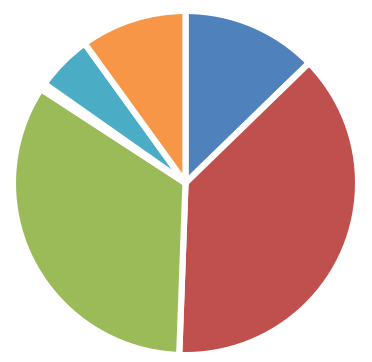

- Kitchen

- Living room

- Bedroom

- Traffic

- Indoor activities

- Outdoor

In brief, our measurements of air pollution and personal exposure showed that during our fieldwork periods there was no detectable difference between the rural and urban participants regarding their average daily personal exposure, neither was there a difference in the AAP level. At the sub-group level, however, some differences appear. Particularly, the cooks in homes using biomass experienced a higher exposure, and the most vulnerable groups were therefore the poorest families who tended to use biomass more often, and elderly women who were often the primary cooks in the families. 


\section{Conclusion and Reflections on Hidden Hazards}

Our study of air quality and personal exposure confirms what other sporadic studies of $\mathrm{PM}_{2.5}$ exposure in rural China have shown, namely that HAP in households using biomass as fuel is at a level that constitutes a real health risk, especially for those doing the cooking. While recognizing the lack of statistical power in our study, we suggest that the enhanced mean exposure found in certain sub-groups, such as biomass users, women, and cooks, was related to the HAP exposure arising from biomass cooking fuel use. We also have sufficient data to conclude that people in these villages prefer to cook with fuel that they themselves regard as being clean and harmless to their health, and that they regard wood as one such form of safe fuel. They believed that coal, rice straw, grass, etc. would be more damaging to their health than wood, and that they had improved their indoor air quality sufficiently by building new and better chimneys in their kitchens in the 1990s when economy improved. We found very strong expressions of concern about industrial air pollution, even resulting in repeated local protests (Hansen and Liu 2018). However, this was not matched by a similar concern about air pollution coming from the burning of biomass in people's own homes. Among the multitude of environmental problems, ranging from air pollution to serious water and soil pollution, the hazard of household cooking with a type of fuel that has a thousand-year history of use was, for understandable reasons, not an issue.

This tendency towards diminishing the risk of HAP was strengthened by the fact that media, local government and national policies on air pollution up to now have paid little attention to HAP. Political and media focus on problems of air pollution has only recently boomed (e.g. Ahlers and Hansen 2017; Yang 2016), and the main attention has so far been towards major urban areas and, implicitly, the effects on the middle class. HAP affects mainly poorer rural households, and especially women and children, who have limited voice in public discussion. Only recently has the government started ambient air monitoring as a pilot project in rural areas, and up to now these data have not been made public. Furthermore, measurements of pollution levels in people's homes and closest neighbourhoods require different methodologies than those currently applied for measuring ambient air, and, for the time being, there are few systematic attempts to start up this kind of research in rural areas. Consequently, rural air pollution and HAP remains a largely hidden hazard for the people it affects, and it remains largely neglected in the public debates about air pollution.

We concur with the conclusion made by William P. Alford et al. already in 2002 (p. 513) regarding air pollution policies in rural areas, that "In the end, perhaps the problem is not only one of constructing institutions or passing laws, but of actually reaching the populace 
with the message about environmental needs and policies". We suggest that if the government continues to expand its monitoring program in rural areas, and, not least, makes the data public and easily available, there is a possibility of finally heightening people's awareness also of the risks of ambient air pollution for rural populations, as has happened in urban areas especially since 2013 . The focus of air pollution control policies has so far been on air quality in cities and on large sources of emissions from the energy, industrial and transport sectors. To the extent that household fuel use has been targeted, it has been as a source of ambient air pollution in cities. However, as we have argued in this article, air pollution is by no means only an urban problem, and its associated health damage is a function of exposure in all microenvironments, including in people's homes. Social practices related to the use of biomass and coal stoves should, therefore, be included in the national and regional air pollution control strategy, and infrastructure for clean fuels should be developed in regions currently lacking access. Our research in villages shows that people respond to policy changes related to household energy use if these policies are understandable, beneficial, and affordable.

\section{References}

Ahlers, A., Hansen M.H. 2017. “Air Pollution: How Will China Win its Self-Declared War Against it?" in Eva Sternfeld (ed.), Routledge Handbook: China's Environmental Policy. London: Routledge.

Alford, William P., Weller, R. P., Hall, L., Polenske, K., Shen Yuanyuan \& Zweig, D. 2002. "The human dimensions of pollution policy implementation: Air quality in rural China". Journal of contemporary China. Vol 11, no. 32, pp. 495-513.

Aunan, K., Ma, Q., Lund, M. T., \& Wang, S. 2018b. "Population-weighted exposure to PM2.5 pollution in China: An integrated approach." Environmental International. Vol. 120, November, pp. 111-120.

Aunan, K., Hansen, M. H., \& Wang, S. 2018a. "Introduction: Air Pollution in China". The China Quarterly. Vol. 234, June, pp. 279-298.

Aunan, Kristin, and Xiao-Chuan Pan. 2004. "Exposure-Response Functions for Health Effects of Ambient Air Pollution Applicable for China - a Meta-Analysis." Science of The Total Environment 329 (1-3): 3-16. https://doi.org/10.1016/j.scitotenv.2004.03.008.

Brunekreef, Bert. 2007. "Health Effects of Air Pollution Observed in Cohort Studies in Europe." Journal of Exposure Science and Environmental Epidemiology 17 (December): S61-65. https://doi.org/10.1038/sj.jes.7500628.

Butt, E. W., Rap, A., Schmidt, A., Scott, et al. 2016. The impact of residential combustion emissions on atmospheric aerosol, human health, and climate. Atmospheric Chemistry and Physics, 16(2), 873-905. doi:10.5194/acp-16-873-2016

Conibear, L., Butt, E. W., Knote, et al. (2018). Residential energy use emissions dominate health impacts from exposure to ambient particulate matter in India. Nat Commun, 9(1), 617. doi:10.1038/s41467-018-02986-7 
Gao, Fangfang. 2017. Huanjing Zhuanbo: Meijie, Gongzhong Yu Shehui 环境转播: 媒介, 公众与社会 [Environmental Communications: Media, Public and Society]. Hangzhou: Zhejiang University Press.

GBD. (2016). Global, regional, and national comparative risk assessment of 79 behavioural, environmental and occupational, and metabolic risks or clusters of risks, 1990-2015: a systematic analysis for the Global Burden of Disease Study 2015. The Lancet, 388(10053), 1659-1724. doi:10.1016/s0140-6736(16)31679-8

Guerreiro, Cristina, Alberto González Ortiz, Frank de Leeuw, Mar Viana, Jan Horálek, and European Environment Agency. 2016. Air Quality in Europe - 2016 Report. http://bookshop.europa.eu/uri?target=EUB:NOTICE:THAL16127:EN.

Hansen, Mette Halskov, and Zhaohui Liu. 2018. "Air Pollution and Grassroots Echoes of 'Ecological Civilization."” The China Quarterly, Vol. 234, June, pp. 220-239.

$\mathrm{Hu}$, Ruolan, Shuxiao Wang, Kristin Aunan, Minjiang Zhao, Zhijian Li, Lu Chen, Zhaohui Liu, Mette Halskov Hansen. " Personal Exposure to $\mathrm{PM}_{2.5}$ in rural areas of Yangtze River Delta, China". (In progress).

Iii, C. Arden Pope, Richard T. Burnett, Michael J. Thun, Eugenia E. Calle, Daniel Krewski, Kazuhiko Ito, and George D. Thurston. 2002. "Lung Cancer, Cardiopulmonary Mortality, and Long-Term Exposure to Fine Particulate Air Pollution." JAMA 287 (9): 1132-41. https://doi.org/10.1001/jama.287.9.1132.

Jacobs, Milena, Guicheng Zhang, Shu Chen, Ben Mullins, Michelle Bell, Lan Jin, Yuming Guo, Rachel Huxley, and Gavin Pereira. 2017. "The Association between Ambient Air Pollution and Selected Adverse Pregnancy Outcomes in China: A Systematic Review." Science of The Total Environment 579 (February): 1179-92. https://doi.org/10.1016/j.scitotenv.2016.11.100.

Jin, Y. L., Ma, X., Wei, H. Z., Liu, F., Chen, X. N., Lan, Y. J., . . Ezzati, M. (2005). Knowledge of hazards from indoor air pollution from household energy use in rural China. Indoor Air 2005: Proceedings of the 10th International Conference on Indoor Air Quality and Climate, Vols 1-5, 3681-3684.

Kasperson, Roger E., and Jeanne X. Kasperson. 2005. "Hidden Hazards.” In The Social Contours of Risk: Publics, Risk Communication \& the Social Amplification of Risk, edited by Jeanne X. Kasperson and Roger E. Kasperson. New York: Routledge.

Li, Hongtao, and Rune Svarverud. 2018. "When London Hit the Headlines: Historical Analogy and the Chinese Media Discourse on Air Pollution." The China Quarterly, no. March.

Liu, J., Mauzerall, D. L., Chen, Q., Zhang, Q., Song, Y., Peng, W., . . Zhu, T. (2016). Air pollutant emissions from Chinese households: A major and underappreciated ambient pollution source. PNAS. doi:10.1073/pnas.1604537113

Matus, Kira, Kyung-Min Nam, Noelle E. Selin, Lok N. Lamsal, John M. Reilly, and Sergey Paltsev. 2012. "Health Damages from Air Pollution in China." Global Environmental Change 22 (1): 55-66. https://doi.org/10.1016/j.gloenvcha.2011.08.006.

Ministry of Environmental Protection of China. 2017. Air pollution control plan for Beijing Tianjin Hebei and its surrounding areas in 2017. http://dqhj.mep.gov.cn/dtxx/201703/t20170323_408663.shtml

Naeher, Luke P., Michael Brauer, Michael Lipsett, Judith T. Zelikoff, Christopher D. Simpson, Jane Q. Koenig, and Kirk R. Smith. 2010. "Woodsmoke Health Effects: A Review." Inhalation Toxicology, July. https://doi.org/10.1080/08958370600985875.

National Bureau of Statistics of China (NBS). 2012. Population Census Office under the State Council and Population and Employment Statistics Department of the National Bureau of Statistics of China, 2012. Tabulation on the 2010 population census of the People's Republic of China. Retrieved from China Statistics Press. 
Nielsen, Chris, Mun S. Ho. 2013. Clearer Skies Over China: Reconciling Air Quality, Climate, and Economic Goals. Cambridge Mss., London: MIT Press.

Office for the Population Census of Zhejiang. 2012. Tabulation on the 2010 Population Census of Zhejiang Province (浙江省人口普查资料). Vol. 1. Hangzhou: China Statistics Press.

Pope, C. A., $3^{\text {rd }}$., Burnett, R. T., Thun, M. J., Calle, E. E., Krewski, D., Ito, K., \& Thurston, G. D. 2002. Lung cancer, cardiopulmonary mortality, and long-term exposure to fine particulate air pollution. JAMA, 287(9), 1132-1141.

Sinton, Jonathan E., Kirk R. Smith, John W. Peabody, Liu Yaping, Zhang Xiliang, Rufus Edwards, and Gan Quan. 2004. "An Assessment of Programs to Promote Improved Household Stoves in China." Energy for Sustainable Development 8 (3): 33-52. https://doi.org/10.1016/S0973-0826(08)60465-2.

The World Bank. 2013. "China - Accelerating Household Access to Clean Cooking and Heating." 83265. The World Bank. http://documents.worldbank.org/curated/en/125491468219579395/ChinaAccelerating-household-access-to-clean-cooking-and-heating.

Wang J, Zhao B, Wang S, Yang F, Xing J, Morawska L, et al. 2017. Particulate matter pollution over China and the effects of control policies. Science of The Total Environment, 584-585: 426-447

WHO. 2010. "WHO Guidelines for Indoor Air Quality : Selected Pollutants - E94535.Pdf." http://www.who.int/indoorair/publications/9789289002134/en/.

WHO. 2014. WHO Guidelines for Indoor Air Quality: Household Fuel Combustion. Geneva, Switzerland: World Health Organization.

Yang, Fan. 2016. "Under the Dome: "Chinese" smog as a viral media event". Critical Studies in Media Communication. Vol. 33, 3, pp. 232-244.

Yin, Peng, Guojun He, Maoyong Fan, Kowk Yan Chiu, Maorong Fan, Chang Liu, An Xue, et al. 2017. "Particulate Air Pollution and Mortality in 38 of China's Largest Cities: Time Series Analysis.” BMJ, March, j667. https://doi.org/10.1136/bmj.j667.

Zhao, B., Zheng, H., Wang, S., KR, S., Lu, X., Aunan, K., et al. (2018). Change in household fuels dominates the decrease in $\mathrm{PM}_{2.5}$ exposure and premature mortality in China in 2005-2015. PNAS (In press.).

Zhejiang Statistics Bureau NBS Survey Office in Zhejiang, ed. 2014. Zhejiang Statistical Yearbook 2014. Hangzhou: China Statistics Press.

http://www.purpleculture.net/zhejiang-statistical-yearbook-2014-p-19243/. 